\title{
TAX DECLARATION RATES VIA AUDITS: A PREDICTION USING MARKOV MODEL
}

\section{DOI: 10.17261/Pressacademia.2017.499 \\ JBEF- V.6-ISS.2-2017(5)-p.97-111}

\author{
Ersin Kıral ${ }^{1}$, Can Mavruk ${ }^{2}$ \\ ${ }^{1}$ Çukurova University, Department of Econometrics, Adana, 01330, Turkey. ekiral@cu.edu.tr \\ ${ }^{2}$ Ömer Halis Demir University, School of Social Sciences, Niğde, 51100, Turkey. can.mavruk@ohu.edu.tr
}

To cite this document

Kıral, E., C. Mavruk (2017). Tax declaration rates via audits: a prediction using markov model. Journal of Business, Economics and Finance (JBEF), V.6, Iss.2, p. 97-111.

Permemant link to this document: http://doi.org/10.17261/Pressacademia.2017.499

Copyright: Published by PressAcademia and limited licenced re-use rights only.

\begin{abstract}
Purpose- This article predicts tax declaration rates by Markov chain model.

Methodology- Four Markov models are constructed for the declaration rates of three tax revenues. Declaration probabilities for the year 2017 are estimated by constructing probability matrices of transitions between classes described for every model. Declaration rates are predicted by the product of the initial probability matrix and transition probability matrix. Limiting matrices of predictions are found. The best Markov model was found by estimating the sum of mean square errors for every model.

Findings- Main results of this study are i) transitions of tax declarations are declining in higher states and improving in lower states, ii) in its best model corporate tax declaration rate is predicted to be between $47 \%$ and $64.5 \%$ in 2017 with a probability of $78 \%$ and would be stable in the same interval at a probability of $60 \%$ in 2038 , iii) in the long run income tax would decrease $€ 20,3$ billion with a probability of $42 \%$ and Value Added Tax would decrease $€ 26,2$ billion with a probability of $40 \%$ and iv) expected declaration rates of income tax, corporate tax and value added tax in 2017 are $52.3 \%, 61.6 \%$ and $62.8 \%$, respectively.

Conclusion- Income tax and Value Added Tax payoffs may substantially decrease from 2015 to 2038 and 2023 respectively. This may cause a revenue deficiency to Turkish Revenue Administration. Therefore Income tax and Value Added Tax audits should be increased. Even though tax revenues increase over time, the declaration rates show a decreasing to stationary or increasing to stationary behavior.
\end{abstract}

Keywords : Tax declaration rates, tax auditing, tax administration, transition probabilities, Markov analysis JEL Codes: C51, H21, M42

\section{INTRODUCTION}

There is no study in the literature about tax declaration rates in connection with Markov modelling. Markov modelling of time series data does not provide sharp predictions. However it certainly provides accurate predictions and stationary probabilities for finite states. In a similar study thirteen tax revenues are predicted using Markov model in the paper by Kıral and Mavruk (2016).

The tax declaration is a decision under uncertainity Allingham and Sandmo (1972). The uncertainity of taxpayers decision on tax declaration has a great importance for tax administration revenues. Therefore tax declaration rates are important indicators of tax revenues. Every year tax administration audits a number of taxpayers and as a result of the audits a base difference is found between actual income and declared income when tax is underdeclared or evaded. Tax administration can determine evaded tax only on a small sample of taxpayers being audited. Therefore an increase in audit rate would always increase declared income. In this study tax declaration rates are calculated and predicted for three tax items such as income tax, corporate tax and value added tax since approximately 64\% of tax revenues in 2015 are from these three taxes.

The objective of this paper is to find the best model predicting tax declaration rates using four Markov Models for each tax. The best of the four has the least sum of the mean square errors. Predictions of tax declaration rates are expected to be stationary and to have a limiting matrix. The rest of this study is organized as follows. In section 2 related literature is given. In section 3 methods for constructing transition probabilities, Markov models and predictive probability matrices, and for finding better model of Markov models and statistical significance of the models are given. In section 4 data of this study 
along with description of the symbols is provided. In section 5 calculations for the three taxes are given. In section 6 a comparison of 2017 predictions of the three taxes, in section 7 a better model for each tax item, in section 8 a comparison of initial probability matrices and limiting matrices, and in section 9 statistical significance of the models are given. In section 10 results of this study are given and discussed, and the study ends with conclusion remarks in section 11.

\section{LITERATURE REVIEW}

Allingham and Sandmo (1972) analyzes income tax evasion by theoretical analysis approach. They analyze taxpayers decision under uncertainity on evading tax in static and dynamic cases. In static case they find the conditions for maximizing taxpayer utility function. They reach the first result that there exists an interior maximum solution. They concluded that an increase in audit rate and fine rate would always increase declared income, and an increase in tax rate would increase tax evasion. Baasch et. al (2010) used Markov models to quantify transitions between successional stages. They presented a solution for converting multivariate ecological time series into transition matrices and demonstrate the applicability of this approach for a data set that resulted from monitoring the succession of sandy dry grassland in a post-mining landscape. They analyzed five transition matrices, four one-step matrices referring to specific periods of transition (1995-1998, 19982001, 2001-2004, 2004-2007), and one matrix for the whole study period (stationary model, 1995-2007).

Büyüktatlı et. al (2013) used initial allocations of investment program with actual spending percentages from the years of 1998-2009 of Turkish Atomic Energy Institute (TAEK) to predict annual allowances from Ministry of Energy and Natural Resources. An estimated percentage of realization of investment program for 2011 and results are interpreted with Markov analysis. Cavers and Vasudevan (2015) directed graph representation of a Markov chain model to study global earthquake sequencing leads to a time series of state-to-state transition probabilities that includes the spatio-temporally linked recurrent events in the recordbreaking sense. A state refers to a configuration comprised of zones with either the occurrence or non-occurrence of an earthquake in each zone in a pre-determined time interval.

Grimshaw and Alexander (2011) used a Markov chain model to forecast outstanding balance of loans in each delinquency state. For that they used a markov chain $X n$ as the delinquency state of a loan in month $n$ and a Markov Chain model for loan accounts that are 'current' this month having a probability of moving next month into 'current', 'delinquent' or 'paidoff' states. They forecasted 'one month ahead' portfolio delinquency balance for a portfolio of loans where each loan is $n_{i}$ months from origination this month $i=1, \ldots, N$. Lazri et.al (2015) adopted a Markovian approach to discern the probabilistic behaviour of the time series of the drought. A transition probability matrix was constructed from drought distribution maps. Markov transition probability formula for four states and a simulation model with an initial probability vector was used to calculate the drought distribution area in the future.

Lukić et. al. (2013) used the stochastic method based on a Markov chain model to predict the annual precipitation in the territory of South Serbia for the period 2009-2013. For this purpose, the precipitation data rainfall recorded on the four synoptic stations were used for the period 1980-2010. Kıral and Mavruk (2016) used one step Markov chain model to predict tax revenues in Turkey for the period 2000-2014. Four Markov models were used for each tax and best predictive model was found by the sum of mean square errors. Usher (1979) discussed that complex non-random or Markovian processes are likely to characterize ecological successions, the transition probability matrix elements not being constant but being functions either of the abundance, or of the rate of change of abundance, of a recipient class.

\section{DATA AND METHODOLOGY}

\subsection{Methodology}

A stochastic process $X=\left\{X_{n}: n \geq 0\right\}$ on a countable set $S$ is a Markov Chain if, for any $i, j \in S$ and $n \geq 0$,

$$
\begin{gathered}
\mathrm{P}\left\{X_{\mathrm{n}+1}=j \mid X_{0}, \ldots, X_{\mathrm{n}}\right\}=\mathrm{P}\left\{X_{\mathrm{n}+1}=j \mid X_{\mathrm{n}}\right\} \\
\mathrm{P}\left\{X_{\mathrm{n}+1}=j \mid X_{\mathrm{n}}=i\right\}=p_{\mathrm{ij}} .
\end{gathered}
$$

The $p_{\mathrm{ij}}$ is the probability that the Markov chain jumps from state $i$ to state $j$. These transition probabilities satisfy

$$
\sum_{j \in S} p_{i j}=1 \forall i \in S
$$

and the matrix $\mathrm{P}=\left(p_{\mathrm{ij}}\right)$ is the transition matrix of the chain. Condition (1), called the Markov property, says that, at any time $n$, the next state $X_{n+1}$ is conditionally independent of the past $X_{0}, \ldots, X_{n-1}$ given the present state $X_{n}$. In other words, the next state is dependent on the past and present only through the present state. Condition (2) simply says the transition probabilities do not depend on the time parameter $n$; the Markov chain is therefore "time-homogeneous". (Serfozo, 2009, p.2). Four Markov models are constructed for each tax and best one for each tax is found. For the four models raw data of tax declaration rates are categorized into five, four, three and two categories by a grouped frequency distribution for each 
model. Transition probability matrix is constructed and multiplied by the initial probability matrix to predict next year's probability matrix. Continuing on this procedure stationary probability matrix is found.

\subsubsection{Construction of Transition Probabilities}

Transition probability matrices are estimated for 2000-2015 for income tax, corporate tax and value added tax declaration rates. The estimator of the transition probabilities is the relative frequency of the actual transitions from phase $i$ to phase $j$, i.e. the observed transitions have to be divided by the sum of the transitions to all other phases (Lipták, 2011, p.141).

In this paper,

$$
p_{i j}=n_{i j} / \sum_{j} n_{i j} \text { for } i, j=\mathrm{A}, \mathrm{B}, \mathrm{C}, \mathrm{D}, \mathrm{E}
$$

where $n_{i j}$ is the number of observed transitions from $i$ to $j, \sum_{j} n_{i j}$ is the sum of observed transitions from $i$ to $j$.

Frequency distribution of the declaration rate intervals must be mutually exclusive (nonoverlapping) and class width must be equal for each interval (Bluman, 2014, p.45-46). Transition probabilities from $X_{i}$ to $X_{j}, i, j=0,1,2, \ldots, m$, can be constructed at time $n$ as the following matrix $0,1,2, \ldots, m$, can be constructed at time $n$ as the following matrix

$$
P_{n}=\left[\begin{array}{cccc}
P_{11} & P_{12} & \ldots & P_{1 m} \\
P_{21} & P_{22} & \ldots & P_{2 m} \\
\vdots & \vdots & \vdots & \vdots \\
P_{m 1} & P_{m 2} & \ldots & P_{m m}
\end{array}\right]
$$

\subsubsection{Prediction}

Declaration rates can be estimated for every year in the period of the study and can be predicted for the years after the last year in the period of the study. Given that data at time $n$ is in state $X_{0}$ and that the data will be in one of states $X_{n} \in$ $\{1,2, \ldots, m\}$ at time $n$, then the data at time $n+1$ can be predicted. Given that transition probability matrix up to the year $n$ is $P_{n}$ and initial probability matrix for the year $n$ is $Q_{n}$ for $n=0,1,2, \ldots$, next year's probability distribution matrix can be estimated by

$$
Q_{n+1}=Q_{n} P_{n}
$$

Initial probability matrices for four Markov models are $1 x$ j row matrices. For after the last year in the period declaration rates can be predicted by

$$
\hat{Q}_{n+1}=\hat{Q}_{n} P_{n}
$$

Prediction matrices have a limiting (stationary) matrix $\hat{Q}$, which can be written as

$$
\lim _{n \rightarrow \infty} \hat{Q}_{n+1}=\hat{Q} .
$$

\subsubsection{Best of Four Markov Models}

For every year of the sample and for every Markov model, mean square error (mse) is calculated by

$$
\frac{1}{m} \sum_{i=1}^{m}\left(r_{i}-\hat{r}_{i}\right)^{2}
$$

where $m$ : the number of states and $m=2,3,4,5, r_{i}$ : realized declaration rate in state $i$ in the year $n+1$ and

$\hat{r}_{i}$ : estimated declaration rate in state $i$ in the year $n+1$.

Estimated matrix at time $n+1$ can be found by

$$
Q_{n+1}=Q_{n} P_{n}=\left[\begin{array}{lllll}
\hat{r}_{1} & \hat{r}_{2} & \hat{r}_{3} & \cdots & \hat{r}_{m}
\end{array}\right]
$$

where $Q_{n}=\left[\begin{array}{llll}r_{1} & r_{2} & \cdots & r_{m}\end{array}\right]$ : the initial probability matrix at time $n$ for $m$ states.

The sum of all mse (smse) for each model is calculated by 


$$
\sum_{n+2}^{k} \frac{1}{m} \sum_{i=1}^{m}\left(r_{i}-\hat{r}_{i}\right)^{2}
$$

where $n$ is the first year and $k$ is the last year in the data.

The least sum MSE gives the best Markov model.

\subsubsection{Statistical Significance of the Models}

Variations between observed and expected frequencies can be tested by constructing a contingency table of frequency distribution of transitions between the states at 0.05 significance level with a degree of freedom.

To validate Markov model, for every year, the value of the $\chi^{2}$ statistic is computed based on the null hypothesis, $\mathrm{H}_{0}$ : model is valid. At 0.05 level of significance and with the degrees of freedom, the $\chi^{2}$ critical value and $\chi^{2}$ test value are estimated. The null hypothesis is not rejected whenever $\chi^{2}$ test value is less than the critical value. Test values are calculated by

$$
\chi^{2}=\sum_{i}\left(r_{i}-\hat{r}_{i}\right)^{2} / \hat{r}_{i}
$$

where $i$ : the number of categories and $i=1, \ldots, m, r_{i}$ : actual probability, $\hat{r}_{i}$ : expected probability

\subsection{Data}

According to Turkish Revenue Administration (TRA) Activity Report 2015, total tax revenue is $464,886,790,000$, income tax collected is $105,393,946,000 €$, corporate tax collected is $37,009,483,000 €$, collected Value Added Tax (VAT) Included is $79,188,287,000 \quad \xi$ and collected VAT on imports is $74,387,089,000$. (http://www.gib.gov.tr/fileadmin/user_upload/VI/GBG/Tablo_22.xls.htm accessed 08.08.2016). This data shows that the total of the three taxes is approximately $64 \%$ of the total tax revenue. Raw data of this study is extracted from inspection results in TRA Activity Reports for the years 2000-2015 (http://www.gib.gov.tr/kurumsal/ stratejik-yonetim/faaliyetraporlari). Data is available as inspected tax base and base difference. Inspected tax base is the declared tax base or declared income. The quotient of declared income and actual income gives tax declaration rates in Table 2. Missing data for the years 2002 and 2010 are completed by regression in SPSS missing value analysis. Inspection results for the years 20002015 are used to construct Tables 3, 4 and 5 for tax declaration rates of income tax, corporate tax and VAT respectively. 2015 inspection results in Table 2 are used to find 2015 tax declaration rates $(X / B)$ in Tables 3, 4 and 5.

\subsubsection{Income Tax Declaration Rates}

Income tax base inspected (declared amount) and base difference (difference between actual income and declared tax base) and declaration rates for the years 2000-2015 are given in Table 3. In the last sixteen years the highest rate in income tax declaration was $98.9 \%$ in 2011 and the lowest realized was $4.2 \%$ in 2006 . Significant ups and downs are observed in the rate data over the given period.

\subsubsection{Corporate Tax Declaration Rates}

Corporate tax income declarations, base difference and declaration rates for years 2000-2015 are given in Table 4. In the last sixteen years the highest declared tax rate was $99.6 \%$ in 2011 and the lowest was $11.8 \%$ in 2007. Corporate tax declaration rates has significant ups and downs over the given period.

\subsubsection{Value Added Tax Declaration Rates}

VAT declarations, base difference and declaration rates for years 2000-2015 are given in Table 5. In the last sixteen years the highest declared tax rate was $96.5 \%$ in 2011 and the lowest was $23.7 \%$ in 2009. VAT declaration rates has significant jumps and falls over the given period.

Table 1 shows the descriptions of some symbols used in this article.

Table 1: Description of Symbols

\begin{tabular}{ll}
\hline Symbols & Description \\
\hline M1 & Markov model 1 \\
M2 & Markov model 2 \\
M3 & Markov model 3 \\
M4 & Markov model 4 \\
Code & A state of declaration rate \\
$A$ & Highest state of a declaration rate \\
$P_{n}$ & Transition probability matrix for the \\
\hline
\end{tabular}




\begin{tabular}{ll}
\hline & year $n$ \\
SY & Stationary year of tax declaration \\
$\mathrm{df}$ & Degree of freedom \\
$\hat{Q}$ & Stationary probability matrix \\
$Q_{n}$ & Initial probability matrix \\
$\chi_{0,05}^{2}$ & Ki-square test value at 0.05 level of \\
\hline
\end{tabular}

Table 2: 2015 Tax Audit Results According To Turkish Tax Administration Audits

\begin{tabular}{|c|c|c|c|c|c|c|}
\hline Tax Type & $\begin{array}{c}\text { \# of Tax Payers } \\
\text { Audited }\end{array}$ & $\begin{array}{l}\text { Declared Income } \\
\text { X (000 })\end{array}$ & $\begin{array}{c}\text { Base } \\
\text { Difference } \\
\text { B-X (000 })\end{array}$ & $\begin{array}{c}\text { Tax Difference } \\
\text { (000も) }\end{array}$ & $\begin{array}{c}\text { Calculated Tax } \\
\text { (000も) }\end{array}$ & $\begin{array}{c}\text { Rate } \\
\text { Declared } X / B\end{array}$ \\
\hline Income & 1,779 & 52,051 & 48,157 & 11,232 & 13,153 & 0.519 \\
\hline Corporate & 491 & 38,046 & 27,709 & 5,190 & 5,529 & 0.579 \\
\hline VAT & 2,104 & $1,229,173$ & 464,869 & 41,539 & 57,313 & 0.726 \\
\hline Special & 38 & 3,353 & 754 & 290 & 359 & 0.816 \\
\hline Bank Ins. & 13 & 851 & 529 & 11 & 34 & 0.617 \\
\hline Stamp & 44 & 59,354 & 110,599 & 1,871 & 1,888 & 0.349 \\
\hline Advance & 1,066 & 32,711 & 81,930 & 8,874 & 9,069 & 0.285 \\
\hline Others & 4,367 & 120,152 & 157,605 & 4,861 & 4,966 & 0.433 \\
\hline Total & 9,902 & $1,535,689$ & 892,152 & 73,868 & 92,310 & 0.6325 \\
\hline
\end{tabular}

Source: TRA, Activity Reports, http://www.gib.gov.tr/kurumsal/stratejik-yonetim/faaliyet-raporlari (5.1.2016) (TRA 20002015).

Table 3: Income Tax Declaration Rates

\begin{tabular}{cccc}
\hline Year & $\begin{array}{c}\text { Declared Income } \boldsymbol{X}(\mathbf{t}) \\
\mathbf{( 1 )}\end{array}$ & $\begin{array}{c}\text { Base Difference } \boldsymbol{B}-\boldsymbol{X}(\mathbf{(}) \\
\mathbf{( 2 )}\end{array}$ & $\begin{array}{c}\text { Declaration Rate (\%) } \\
\mathbf{( 1 )} / \mathbf{( 1 ) + ( 2 )}\end{array}$ \\
\hline 2000 & $21,448,826$ & $131,855,163$ & 14 \\
2001 & $16,029,993$ & $112,399,579$ & 12.5 \\
2002 & $16,029,993^{*}$ & $131,855,163^{*}$ & 10.8 \\
2003 & $53,664,347$ & $98,700,897$ & 35.2 \\
2004 & $95,385,634$ & $117,625,705$ & 44.8 \\
2005 & $82,221,251$ & $187,773,866$ & 30.5 \\
2006 & $36,155,770$ & $834,488,383$ & 4.2 \\
2007 & $73,393,391$ & $553,781,491$ & 11.7 \\
2008 & $165,504,453$ & $432,502,457$ & 27.7 \\
2009 & $52,452,224$ & $217,014,074$ & 19.5 \\
2010 & $16,029,993^{*}$ & $18,476,344^{*}$ & 46.5 \\
2011 & $1,586,197,618$ & $18,430,305$ & 98.9 \\
2012 & $96,143,976$ & $25,582,141$ & 79 \\
2013 & $19,523,920$ & $18,476,344$ & 51.4 \\
2014 & $34,742,733$ & $26,826,589$ & 56.4 \\
2015 & $52,050,730$ & $48,157,004$ & 51.9 \\
\hline
\end{tabular}

Source: Own Elaboration, " Estimated by SPSS Missing Value Analysis- Regression 
Table 4: Corporate Tax Declaration Rates

\begin{tabular}{cccc}
\hline Year & Declared Income $\boldsymbol{X}(\boldsymbol{\xi})$ & Base Difference $\boldsymbol{B} \boldsymbol{X}(\boldsymbol{\xi})$ & Declaration Rate (\%) \\
\hline 2000 & $29,443,990$ & $170,079,633$ & 14.8 \\
2001 & $71,369,019$ & $144,037,269$ & 33.1 \\
2002 & $71,369,019^{*}$ & $312,024,421^{*}$ & 18.6 \\
2003 & $91,985,678$ & $312,024,421$ & 29.5 \\
2004 & $827,247,790$ & $1,300,020,818$ & 38.9 \\
2005 & $516,441,597$ & $1,292,700,622$ & 28.5 \\
2006 & $381,244,134$ & $877,826,392$ & 30.2 \\
2007 & $222,611,118$ & $1,658,821,068$ & 11.8 \\
2008 & $474,464,700$ & $2,141,819,149$ & 18.1 \\
2009 & $2,246,755,090$ & $5,217,618,792$ & 30.1 \\
2010 & $9,888,342^{*}$ & $10,625,315^{*}$ & 51.2 \\
2011 & $4,251,799,781$ & $18,600,315$ & 99.6 \\
2012 & $15,694,708$ & $10,625,304$ & 59.6 \\
2013 & $9,888,342$ & $9,435,351$ & 51.2 \\
2014 & $39,222,657$ & $12,231,106$ & 76.2 \\
2015 & $38,045,708$ & $27,709,318$ & 57.9 \\
\hline
\end{tabular}

Source: Own Elaboration, ${ }^{*}$ Estimated by SPSS Missing Value Analysis- Regression

Table 5: VAT Declaration Rates

\begin{tabular}{cccc}
\hline Year & Declared Income X (も) & Base Difference B-X (も) & Declaration Rate (\%) \\
\hline 2000 & $243,428,422$ & $105,167,009$ & 69.8 \\
2001 & $127,302,400$ & $172,138,684$ & 42.5 \\
2002 & $243,428,422^{*}$ & $334,385,008^{*}$ & 42.1 \\
2003 & $662,220,809$ & $246,897,979$ & 72.8 \\
2005 & $1,385,551,886$ & $1,530,445,020$ & 47.5 \\
2006 & $1,049,336,007$ & $1,482,289,093$ & 41.4 \\
2007 & $1,746,829,450$ & $507,541,737$ & 77.5 \\
2008 & $1,786,847,392$ & $668,431,089$ & 72.8 \\
2009 & $399,139,277$ & $481,729,811$ & 45.3 \\
2010 & $2,218,678,268$ & $7,132,560,056$ & 23.7 \\
2011 & $1,385,551,886^{*}$ & $246,897,9799^{*}$ & 84.9 \\
2012 & $9,136,386,241$ & $334,385,008$ & 96.5 \\
2013 & $3,746,260,371$ & $274,356,674$ & 93.2 \\
2014 & $800,703,515$ & $221,229,335$ & 78.4 \\
2015 & $2,246,873,937$ & $255,122,508$ & 89.8 \\
\hline
\end{tabular}

Source: Own Elaboration, "Estimated by SPSS Missing Value Analysis - Regression 


\section{FINDINGS AND DISCUSSIONS}

Transition probability matrices with respect to Markov models, predictions and stationarity are calculated for the three taxes.

\subsection{Income Tax}

Income tax declaration rates from largest to smallest are classified as A, B, C, D, E in model 1, as A, B, C, D in model 2, as A, $B, C$ in model 3 and as $A$ and $B$ in model 4. Income tax declaration rates, codes and transitions for all Markov models are shown in Table 7 for the years 2000-2015.

\subsubsection{Markov Models and Transition Probability Matrices}

Classification of income tax declaration rates and transition probability matrices are given in Table 6 . This table shows that declaration rates are over $52 \%$ in three categories of model 1, in two categories of model 2, in two categories of model 3 and in one category of model 4.

\subsubsection{Prediction}

Given that 2015 income tax declaration rate which is $51.9 \%$ is in state $C$ and that income tax will be in one of states A, B, C, $D$ or $E$ in 2016, income tax declaration rates for 2017 and later years are predicted by (5) and the predictions are given in Table 8.

\subsubsection{Stationarity}

Limiting matrices are estimated in Excel by formula (6) for all models. According to four models, all probabilities become stationary in 2038, 2017, 2039 and 2036 respectively.

\subsubsection{Statistical Significance of The Model}

In model 1 of income tax, variations between observed and expected frequencies can be tested by constructing a contingency table of frequency distribution of transitions between the states at 0.05 significance level with $16 \mathrm{df}$. Since chi square test value 23.87 is less than critical value $26.296, \mathrm{H}_{0}$ is not rejected. This shows that there is no significant variations. The values in paranthesis in the Table 9 are expected frequencies which are found from (row sum $x$ column sum)/total. Table 9 shows that transitions in higher realization states are declining and those in lower states rates are improving in model 1.

\subsubsection{Technology}

All calculations in this study are done using Excel and TI-36XPro. Prediction matrices and limiting matrices are estimated using Excel. The sum of mean square errors, classes of Markov models and all other simple calculations are done using TI36XPro.

Table 6: Income Tax Markov Models and Transition Probability Matrices

\begin{tabular}{|c|c|c|c|c|c|c|c|c|c|c|c|c|}
\hline \multirow{2}{*}{$\begin{array}{c}\text { Model } 1 \\
\text { Classes (\%) }\end{array}$} & \multicolumn{6}{|c|}{ Transition Matrix } & \multicolumn{2}{|c|}{ Model 2} & \multicolumn{4}{|c|}{ Transition Matrix } \\
\hline & & A & B & $\mathrm{C}$ & D & $\mathrm{E}$ & Classes (\%) & & $A$ & B & $C$ & $\mathrm{D}$ \\
\hline $80.2 \leq r$ & $A$ & 0 & 1 & 0 & 0 & 0 & $75.3 \leq r$ & $A$ & $1 / 2$ & 0 & $1 / 2$ & 0 \\
\hline $61.2 \leq r \leq 80.1$ & B & 0 & 0 & 1 & 0 & 0 & $51.6 \leq r \leq 75.2$ & $B$ & 0 & 1 & 0 & 0 \\
\hline $42.2 \leq r \leq 61.1$ & C & $1 / 4$ & 0 & $1 / 2$ & $1 / 4$ & 0 & $27.9 \leq r \leq 51.5$ & $\mathrm{C}$ & $1 / 5$ & $1 / 5$ & $2 / 5$ & $1 / 5$ \\
\hline $23.2 \leq r \leq 42.1$ & $\mathrm{D}$ & 0 & 0 & $1 / 3$ & 0 & $2 / 3$ & $r \leq 27.8$ & $D$ & 0 & 0 & $2 / 7$ & $5 / 7$ \\
\hline$r \leq 23.1$ & $\mathrm{E}$ & 0 & 0 & $1 / 6$ & $1 / 3$ & $1 / 2$ & & & & & & \\
\hline Model 3 & & \multicolumn{4}{|c|}{ Transition Matrix } & & Model 4 & \multicolumn{5}{|c|}{ Transition Matrix } \\
\hline Classes (\%) & & \multicolumn{2}{|c|}{ A } & \multicolumn{2}{|l|}{ B } & C & Classes (\%) & & \multicolumn{2}{|c|}{$A$} & \multicolumn{2}{|c|}{$B$} \\
\hline $67.4 \leq r$ & $A$ & \multicolumn{2}{|c|}{$1 / 2$} & \multicolumn{2}{|l|}{$1 / 2$} & 0 & $51.6 \leq r$ & $A$ & \multicolumn{2}{|c|}{$3 / 4$} & \multicolumn{2}{|c|}{$1 / 4$} \\
\hline $35.8 \leq r \leq 67.3$ & B & \multicolumn{2}{|c|}{$1 / 4$} & \multicolumn{2}{|l|}{$1 / 2$} & $1 / 4$ & \multirow[t]{2}{*}{$r \leq 51.5$} & B & \multirow{2}{*}{\multicolumn{2}{|c|}{$1 / 11$}} & \multirow{2}{*}{\multicolumn{2}{|c|}{$10 / 11$}} \\
\hline$r \leq 35.7$ & $\mathrm{C}$ & $c$ & & $2 / 9$ & & $7 / 9$ & & & & & & \\
\hline
\end{tabular}

Source: Own Elaboration 
Table 7: Classification of Income Tax Declaration Rates Based On Inspections By Audit Officers and Transitions Between States

\begin{tabular}{cccccccccc}
\hline Year & $\begin{array}{c}\text { Declaration Rate } \\
\boldsymbol{X} / \mathbf{B}(\%)\end{array}$ & M1 Code & M1 & M2 Code & M2 & M3 Code & M3 & M4 Code & M4 \\
\hline 2000 & 14 & E & & D & & C & & B & \\
2001 & 12.5 & E & EE & D & DD & C & CC & B & BB \\
2002 & 10.8 & E & EE & D & DD & C & CC & B & BB \\
2003 & 35.2 & D & ED & C & DC & C & CC & B & BB \\
2004 & 44.8 & C & DC & C & CC & B & CB & B & BB \\
2005 & 30.5 & D & CD & C & CC & C & BC & B & BB \\
2006 & 4.2 & E & DE & D & CD & C & CC & B & BB \\
2007 & 11.7 & E & EE & D & DD & C & CC & B & BB \\
2008 & 27.7 & D & ED & D & DD & C & CC & B & BB \\
2009 & 19.5 & E & DE & D & DD & C & CC & B & BB \\
2010 & 46.5 & C & EC & C & DC & B & CB & B & BB \\
2011 & 98.9 & A & CA & A & CA & A & BA & A & BA \\
2012 & 79 & B & AB & A & AA & A & AA & A & AA \\
2013 & 51.4 & C & BC & C & AC & B & AB & B & AB \\
2014 & 56.4 & C & CC & B & CB & B & BB & A & AA \\
2015 & 51.9 & C & CC & B & BB & B & BB & A & AA \\
\hline Source: Own Elaboration & & & & & & & & &
\end{tabular}

Source: Own Elaboration

Table 8: Income Tax Declaration Rates Predictions for 2017

\begin{tabular}{llllllll}
\hline $\begin{array}{c}\text { Declaration Interval } \\
\text { (\%) }\end{array}$ & \multicolumn{1}{c}{ M1 } & \multicolumn{1}{c}{$\begin{array}{c}\text { Declaration } \\
\text { Interval (\%) }\end{array}$} & M2 & $\begin{array}{c}\text { Declaration Interval } \\
\text { (\%) }\end{array}$ & M3 & $\begin{array}{c}\text { Declaration } \\
\text { Interval (\%) }\end{array}$ & M4 \\
\hline$r \leq 23.1$ & 0.17 & $r<27.8$ & 0 & $r \leq 35.7$ & 0.32 & $r \leq 51.5$ & 0.52 \\
$23.2 \leq r \leq 42.1$ & 0.125 & $27.9 \leq r \leq 51.5$ & 0 & $35.8 \leq r \leq 67.3$ & 0.43 & $51.6 \leq r$ & 0.48 \\
$42.2 \leq r \leq 61.1$ & 0.33 & $51.6 \leq r \leq 75.2$ & 1 & $67.4 \leq r$ & 0.25 & & \\
$61.2 \leq r \leq 80.1$ & 0.25 & $75.3 \leq r$ & 0 & & & & \\
$80.2 \leq r$ & 0.125 & & & & & & \\
\hline
\end{tabular}

Table 9: Contingency Table of Observed and Expected Income Tax Declaration Rates of Model 1

\begin{tabular}{|c|c|c|c|c|c|c|}
\hline & A & B & C & D & $E$ & Total \\
\hline A & $0(0.07)$ & $1(0.07)$ & $0(0.33)$ & $0(0.33)$ & $0(0.33)$ & 1 \\
\hline B & $0(0.07)$ & $0(0.07)$ & $1(0.33)$ & $0(0.33)$ & $0(0.33)$ & 1 \\
\hline C & $1(0.27)$ & $0(0.27)$ & $2(1.33)$ & $1(0.80)$ & $0(1.33)$ & 4 \\
\hline D & $0(0.20)$ & $0(0.20)$ & $1(1)$ & $0(0.60)$ & $2(1)$ & 3 \\
\hline E & $0(0.40)$ & $0(0.40)$ & $1(2)$ & $2(1.20)$ & $3(2)$ & 6 \\
\hline Total & 1 & 1 & 5 & 3 & 5 & 15 \\
\hline
\end{tabular}




\subsection{Corporate Tax}

Corporate tax declaration rates, codes and transitions for four Markov models are shown for the years 2000-2015 in Table 11.

\subsubsection{Markov Models and Transition Probability Matrices}

Table 10 shows that in three categories of model 1, in two categories of model 2 and model 3, in one category of model 4 , declaration rates are over 58\% between 2000 and 2015. Classification of corporate tax declaration rates and transition probability matrices are given in Table 10.

\subsubsection{Prediction}

Given that 2015 corporate tax declaration rate $57.9 \%$ is in state $C$ and that corporate tax will be in one of states A, B, C, D or $E$ in 2016, corporate tax declaration rates for 2017 and later years are predicted by (5) and the predictions for 2017 are given in Table 12.

\subsubsection{Stationarity}

Limiting matrices are estimated in Excel by formula (6) for all models of corporate tax. According to four models, all probabilities become stationary in 2038, 2041, 2037 and 2030 respectively.

\subsubsection{Statistical Significance of The Model}

In model 1 of corporate tax declarations, variations between observed and expected frequencies can be tested by constructing a contingency table of frequency distribution of transitions between the states at 0,05 significance level with $16 \mathrm{df}$. Since chi square test value 22,85 is less than critical value $26,296, \mathrm{H}_{0}$ is not rejected. This shows that there is no significant variations. The values in paranthesis in the Table 13 are expected frequencies which are found from (row sum $X$ column sum)/total. Table 13 shows that transitions in higher realization states are declining and in lower states except $D$ are improving in model 1.

Table 10: Corporate Tax Declaration Rates Markov Models and Transition Probability Matrices

\begin{tabular}{|c|c|c|c|c|c|c|c|c|c|c|c|c|}
\hline \multirow{2}{*}{$\begin{array}{c}\text { Model } 1 \\
\text { Classes (\%) }\end{array}$} & & \multicolumn{5}{|c|}{ Transition Matrix } & \multirow{2}{*}{$\begin{array}{c}\text { Model } 2 \\
\text { Classes (\%) }\end{array}$} & & \multicolumn{4}{|c|}{ Transition Matrix } \\
\hline & & A & B & C & $\mathrm{D}$ & $\mathrm{E}$ & & & A & B & C & $\mathrm{D}$ \\
\hline $82.2 \leq r$ & A & 0 & 0 & 1 & 0 & 0 & $77.8 \leq r$ & A & 0 & 1 & 0 & 0 \\
\hline $64.6 \leq r \leq 82.1$ & B & 0 & 0 & 1 & 0 & 0 & $55.8 \leq r \leq 77.7$ & B & 0 & $1 / 2$ & $1 / 2$ & 0 \\
\hline $47 \leq r \leq 64.5$ & C & $1 / 3$ & $1 / 3$ & $1 / 3$ & 0 & 0 & $33.8 \leq r \leq 55.7$ & C & $1 / 3$ & $1 / 3$ & 0 & $1 / 3$ \\
\hline $29.4 \leq r \leq 46.9$ & $\mathrm{D}$ & 0 & 0 & $1 / 5$ & $1 / 5$ & $3 / 5$ & $r \leq 33.7$ & $D$ & 0 & 0 & $2 / 9$ & $7 / 9$ \\
\hline$r \leq 29.3$ & $E$ & 0 & 0 & 0 & $4 / 5$ & $1 / 5$ & & & & & & \\
\hline Model 3 & & \multicolumn{5}{|c|}{ Transition Matrix } & Model 4 & \multicolumn{5}{|c|}{ Transition Matrix } \\
\hline Classes (\%) & & & $A$ & B & & C & Classes (\%) & & & $A$ & & B \\
\hline $70.4 \leq r$ & $A$ & & 0 & 1 & & 0 & $55.8 \leq r$ & A & & $2 / 3$ & & $1 / 3$ \\
\hline $41.1 \leq r \leq 70.3$ & B & & $2 / 3$ & $1 / 3$ & & 0 & $r \leq 55.7$ & B & & $1 / 6$ & & $5 / 6$ \\
\hline$r \leq 41$ & $C$ & & 0 & $1 / 1$ & & $9 / 10$ & & & & & & \\
\hline
\end{tabular}

Source: Own Elaboration 
Table 11: Classification of Corporate Tax Declaration Rates Based On Inspections By Audit Officers and Transitions Between States

\begin{tabular}{cccccccccc}
\hline Year & $\begin{array}{c}\text { Declaration } \\
\text { Rates (\%) }\end{array}$ & M1 Code & M1 & M2 Code & M2 & M3 Code & M3 & M4 Code & M4 \\
\hline 2000 & 14.8 & E & & D & & C & & B & \\
2001 & 33.1 & D & ED & D & DD & C & CC & B & BB \\
2002 & 18.6 & E & DE & D & DD & C & CC & B & BB \\
2003 & 29.5 & D & ED & D & DD & C & CC & B & BB \\
2004 & 38.9 & D & DD & C & DC & C & CC & B & BB \\
2005 & 28.5 & E & DE & D & CD & C & CC & B & BB \\
2006 & 30.2 & D & ED & D & DD & C & CC & B & BB \\
2007 & 11.8 & E & DE & D & DD & C & CC & B & BB \\
2008 & 18.1 & E & EE & D & DD & C & CC & B & BB \\
2009 & 30.1 & D & ED & D & DD & C & CC & B & BB \\
2010 & 51.2 & C & DC & C & DC & B & CB & B & BB \\
2011 & 99.6 & A & CA & A & CA & A & BA & A & BA \\
2012 & 59.6 & C & AC & B & AB & B & AB & A & AA \\
2013 & 51.2 & C & CC & C & BC & B & BB & B & AB \\
2014 & 76.2 & B & CB & B & CB & A & BA & A & BA \\
2015 & 57.9 & C & BC & B & BB & B & AB & A & AA \\
\hline Source: Own Elaboration & & & & & & & &
\end{tabular}

Table 12: Corporate Tax Declaration Rate Predictions for 2017

\begin{tabular}{cccccccc}
\hline $\begin{array}{c}\text { Declaration } \\
\text { Interval (\%) }\end{array}$ & M1 & $\begin{array}{c}\text { Declaration } \\
\text { Interval (\%) }\end{array}$ & M2 & $\begin{array}{c}\text { Declaration } \\
\text { Interval (\%) }\end{array}$ & M3 & $\begin{array}{c}\text { Declaration } \\
\text { Interval (\%) }\end{array}$ & M4 \\
\hline$r \leq 29.3$ & 0 & $r<33.7$ & 0.21 & $r \leq 41$ & 0 & $r \leq 55.7$ & 0.58 \\
$29.4 \leq r \leq 46.9$ & 0 & $33.8 \leq r \leq 55.7$ & 0.25 & $41.1 \leq r \leq 70.3$ & 0.48 & $55.8 \leq r$ & 0.42 \\
$47 \leq r \leq 64.5$ & 0.78 & $55.8 \leq r \leq 77.7$ & 0.46 & $70.4 \leq r$ & 0.52 & & \\
$64.6 \leq r \leq 82.1$ & 0.11 & $77.8 \leq r$ & 0.08 & & & & \\
$82.2 \leq r$ & 0.11 & & & & & &
\end{tabular}

Table 13: Contingency Table of Observed and Expected Corporate Tax Declaration Rates of Model 1

\begin{tabular}{|c|c|c|c|c|c|c|}
\hline & A & B & C & D & $\mathbf{E}$ & Total \\
\hline A & $0(0.07)$ & $0(0.07)$ & $1(0.27)$ & $0(0.33)$ & $0(0.27)$ & 1 \\
\hline B & $0(0.07)$ & $0(0.07)$ & $1(0.27)$ & $0(0.33)$ & $0(0.27)$ & 1 \\
\hline C & $1(0.20)$ & $1(0.20)$ & $1(0.80)$ & $0(1)$ & $0(0.80)$ & 3 \\
\hline D & $0(0.33)$ & $0(0.33)$ & 1 (1.33) & 1 (1.67) & $3(1.33)$ & 5 \\
\hline $\mathbf{E}$ & $0(0.33)$ & $0(0.33)$ & $0(1.33)$ & $4(1.67)$ & $1(1.33)$ & 5 \\
\hline Total & 1 & 1 & 4 & 5 & 4 & 15 \\
\hline
\end{tabular}

\subsection{Value Added Tax}

For the years 2000-2015, VAT declaration rates, codes and transitions for four Markov models are shown in Table 15.

\subsubsection{Markov Models and Transition Probability Matrices}

Classification of VAT declaration rates and transition probability matrices are given in Table 14 . This table shows that in two categories of model 1 and model 2, in one category of model 3 and model 4 , declaration rates are over $72.6 \%$ between 2000 and 2015. 


\subsubsection{Prediction}

Given that 2015 VAT declaration rate $72,6 \%$ is in state B and that income tax will be in one of states A, B, C, D or E in 2016, income tax declaration rates for 2017 and later years are predicted by (5). The predictions for 2017 are given in Table 16.

\subsubsection{Stationarity}

Limiting matrices are estimated in Excel by formula (6) for all models of VAT tax. According to four models, all probabilities become stationary in 2027, 2023, 2019 and 2021 respectively.

\subsubsection{Statistical Significance of the Model}

In model 2 of VAT, variations between observed and expected frequencies can be tested by constructing a contingency table of frequency distribution of transitions between the states at 0.05 significance level with $9 \mathrm{df}$. Since chi square test value 12.478 is less than critical value $16.919, H_{0}$ is not rejected. This shows that there is no significant variations. The values in the paranthesis in Table 17 are expected frequencies which are found from (row sum X column sum)/total. Table 17 shows that transitions in higher declaration states are declining and in lower states are improving in model 2.

Table 14: VAT - Markov Models and Transition Probability Matrices

\begin{tabular}{|c|c|c|c|c|c|c|c|c|c|c|c|c|}
\hline \multirow{2}{*}{$\begin{array}{c}\text { Model } 1 \\
\text { Classes (\%) }\end{array}$} & \multicolumn{6}{|c|}{ Transition Matrix } & \multicolumn{2}{|l|}{ Model 2} & \multicolumn{4}{|c|}{ Transition Matrix } \\
\hline & & $A$ & B & $\mathrm{C}$ & D & $\mathrm{E}$ & Classes (\%) & & $A$ & B & C & $\mathrm{D}$ \\
\hline $82.1 \leq r$ & A & $1 / 2$ & $1 / 2$ & 0 & 0 & 0 & $78.6 \leq r$ & A & $1 / 2$ & $1 / 2$ & 0 & 0 \\
\hline $67.5 \leq r \leq 82$ & B & $1 / 5$ & $1 / 5$ & 0 & $3 / 5$ & 0 & $60.3 \leq r \leq 78.5$ & B & $1 / 5$ & $1 / 5$ & $3 / 5$ & 0 \\
\hline $52.9 \leq r \leq 67.4$ & $\mathrm{C}$ & 0 & 0 & 0 & 0 & 0 & $42 \leq r \leq 60.2$ & C & 0 & $1 / 4$ & $1 / 4$ & $1 / 2$ \\
\hline $38.3 \leq r \leq 52.8$ & $\mathrm{D}$ & $1 / 5$ & $1 / 5$ & 0 & $2 / 5$ & $1 / 5$ & $r \leq 41.9$ & D & $1 / 2$ & $1 / 2$ & 0 & 0 \\
\hline$r \leq 38.2$ & $\mathrm{E}$ & 1 & 0 & 0 & 0 & 0 & & & & & & \\
\hline Model 3 & \multicolumn{6}{|c|}{ Transition Matrix } & Model 4 & \multicolumn{5}{|c|}{ Transition Matrix } \\
\hline Classes (\%) & \multicolumn{3}{|c|}{ A } & B & \multicolumn{2}{|c|}{ C } & Classes (\%) & & \multicolumn{2}{|c|}{ A } & \multicolumn{2}{|c|}{ B } \\
\hline $72.3 \leq r$ & A & \multicolumn{2}{|c|}{$3 / 4$} & 0 & \multicolumn{2}{|c|}{$1 / 4$} & $60.2 \leq r$ & $A$ & \multicolumn{2}{|c|}{$2 / 3$} & \multicolumn{2}{|c|}{$1 / 3$} \\
\hline $48 \leq r \leq 72.2$ & B & \multicolumn{2}{|c|}{0} & 0 & \multicolumn{2}{|c|}{1} & $r \leq 60.1$ & B & \multirow{2}{*}{\multicolumn{2}{|c|}{$1 / 2$}} & \multicolumn{2}{|c|}{$1 / 2$} \\
\hline$r \leq 47.9$ & C & \multicolumn{2}{|c|}{$1 / 2$} & 0 & \multicolumn{2}{|c|}{$1 / 2$} & & & & & & \\
\hline
\end{tabular}

Source: Own Elaboration

Table 15: Classification of VAT Declaration Rates Based On Inspections By Audit Officers and Transitions Between States

\begin{tabular}{cccccccccc}
\hline Year & $\begin{array}{c}\text { Declaration } \\
\text { Rate (\%) }\end{array}$ & M1 Code & M1 & M2 Code & M2 & M3 Code & M3 & M4 Code & M4 \\
\hline 2000 & 69.8 & B & & B & & B & & A & \\
2001 & 42.5 & D & BD & C & BC & C & BC & B & AB \\
2002 & 42.1 & D & DD & C & CC & C & CC & B & BB \\
2003 & 72.8 & B & DA & B & CB & A & CA & A & BA \\
2004 & 47.5 & D & BD & C & BC & C & AC & B & AB \\
2005 & 41.4 & D & DD & D & CD & C & CC & B & BB \\
2006 & 77.5 & B & DB & B & DB & A & CA & A & BA \\
2007 & 72.8 & B & BB & B & BB & A & AA & A & AA \\
2008 & 45.3 & D & BD & C & BC & C & AC & B & AB \\
2009 & 23.7 & E & DE & D & CD & C & CC & B & BB \\
2010 & 85.9 & A & EA & A & DA & A & CA & A & BA \\
2011 & 96.5 & A & AA & A & AA & A & AA & A & AA \\
2012 & 93.2 & A & AA & A & AA & A & AA & A & AA \\
2013 & 78.4 & B & AB & B & AB & A & AA & A & AA \\
2014 & 89.8 & A & BA & A & BA & A & AA & A & AA \\
2015 & 72.6 & B & AB & B & AB & A & AA & A & AA \\
\hline
\end{tabular}

Source: Own Elaboration 
Table 16: VAT Declaration Rate Predictions for 2017

\begin{tabular}{cccccccc}
\hline $\begin{array}{c}\text { Declaration } \\
\text { Interval (\%) }\end{array}$ & M1 & $\begin{array}{c}\text { Declaration } \\
\text { Interval (\%) }\end{array}$ & M2 & $\begin{array}{c}\text { Declaration } \\
\text { Interval (\%) }\end{array}$ & M3 & $\begin{array}{c}\text { Declaration } \\
\text { Interval (\%) }\end{array}$ & M4 \\
\hline$r \leq 38.2$ & 0.12 & $r \leq 41.9$ & 0.30 & $r \leq 47.9$ & 0.33 & $r \leq 60.1$ & 0.39 \\
$38.3 \leq r \leq 52.8$ & 0.36 & $42 \leq r \leq 60.2$ & 0.27 & $48 \leq r \leq 72.2$ & 0 & $60.2 \leq r$ & 0.61 \\
$52.9 \leq r \leq 67.4$ & 0 & $60.3 \leq r \leq 78.3$ & 0.29 & $72.3 \leq r$ & 0.67 & & \\
$67.5 \leq r \leq 82$ & 0.26 & $78.6 \leq r$ & 0.14 & & & & \\
$82.1 \leq r$ & 0.26 & & & & & & \\
\hline
\end{tabular}

Source: Own Elaboration

Table 17: Contingency Table of Observed and Expected VAT Declaration Rates of Model 1

\begin{tabular}{cccccc}
\hline & A & B & C & D & Total \\
\hline A & $2(1.07)$ & $2(1.33)$ & $0(1.07)$ & $0(0.53)$ & 4 \\
B & $1(1.33)$ & $1(1.67)$ & $3(1.33)$ & $0(0.67)$ & 5 \\
C & $0(1.07)$ & $1(1.33)$ & $1(1.07)$ & $2(0.53)$ & 4 \\
D & $1(0.53)$ & $1(0.67)$ & $0(0.53)$ & $0(0.27)$ & 2 \\
\hline Total & 4 & 5 & 4 & 2 & 15 \\
\hline
\end{tabular}

Source: Own Elaboration

\section{- Comparison of Predictions of Tax Declarations for 2017}

Given that 2015 tax declaration rate is in state A, B, C, D or E and will be in one of these states in 2016, declaration rate matrices are predicted for 2017 and later years by formula (5). Predictions for the three tax declaration rates are combined in Table 18.

\section{- A Better Model For Tax Revenues}

Sum of mean square errors for a better model of each tax is given in Table 19. Error values in bold indicates the better model.

\section{- Comparison of Initial Probability Matrices and Stationarity of Tax Declarations}

Stationary matrices for tax declarations are found for every model and are given in Table 20. $Q_{0}$ is initial probability matrix for the 2015 declaration rates of tax revenues and $S Y$ is the stationarity year when probability matrix becomes stable.

\section{- Statistical Significance of Markov Model}

In the present study, the validity of model is checked for the years 2011 and 2015 . The degrees of freedom (df), $\chi^{2}$ critical values, test values and hypothesis are given in Table 20 . The null hypothesis is not rejected since $\chi^{2}$ test value is less than the critical value. The values of the $\chi^{2}$ test are less than $\chi^{2}$ critical values for the years 2011 and 2015, which implies that the estimated declaration rates of tax revenues and the actual declaration rates of tax revenues are not significantly different. Table 21 results show that Markov model is valid.

Table 18: 2017 Prediction of Tax Declaration Rates Based on Inspections by Audit Officers

\begin{tabular}{|c|c|c|c|c|c|c|c|c|c|c|c|c|}
\hline & & A & B & C & D & $E$ & & A & B & C & D & $E$ \\
\hline \multirow{4}{*}{ 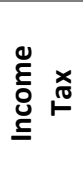 } & M1 & 0.125 & 0.25 & 0.33 & 0.125 & 0.17 & \multirow{4}{*}{ 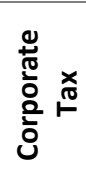 } & 0.11 & 0.11 & 0.78 & 0 & 0 \\
\hline & $\mathrm{M} 2$ & 0 & 1 & 0 & 0 & & & 0.08 & 0.46 & 0.25 & 0.21 & \\
\hline & M3 & 0.25 & 0.43 & 0.32 & & & & 0.52 & 0.48 & 0 & & \\
\hline & M4 & 0.48 & 0.52 & & & & & 0.42 & 0.58 & & & \\
\hline \multirow{4}{*}{$\stackrel{\leftarrow}{\lessgtr}$} & M1 & 0.23 & 0.29 & 0 & 0.36 & 0.12 & & & & & & \\
\hline & $\mathrm{M} 2$ & 0.14 & 0.29 & 0.27 & 0.30 & & & & & & & \\
\hline & M3 & 0.67 & 0 & 0.33 & & & & & & & & \\
\hline & M4 & 0.61 & 0.39 & & & & & & & & & \\
\hline
\end{tabular}


Table 19: Tax Declarations SMSE

\begin{tabular}{ccccc}
\hline Tax Revenues & \multicolumn{4}{c}{ Sum of Mean Square Errors (SMSE) } \\
\hline & Model 1 & Model 2 & Model 3 & Model 4 \\
Income tax & $\mathbf{3 . 4 4}$ & 3.68 & 4.15 & 7.59 \\
Corporate tax & $\mathbf{3 . 4 5}$ & 4.71 & 5.02 & 6.56 \\
Vat & 3.86 & $\mathbf{3 . 3 2}$ & 3.66 & 4.47 \\
\hline
\end{tabular}

Source: Own Elaboration

Table 20: Stationary Matrices of Tax Declarations

\begin{tabular}{|c|c|c|c|c|c|c|}
\hline \multirow[b]{2}{*}{ Tax Revenues } & \multicolumn{3}{|c|}{ Markov Model 1} & \multicolumn{3}{|c|}{ Markov Model 2} \\
\hline & $Q_{n}$ & $\lim _{n \rightarrow \infty} \hat{Q}_{n+1}=\hat{Q}$ & $S Y$ & $Q_{n}$ & $\lim _{n \rightarrow \infty} \hat{Q}_{n+1}=\hat{Q}$ & $S Y$ \\
\hline Income tax & 00100 & 24. 18. 10. 10. 10. & 2038 & 0100 & $\begin{array}{llll}0 & 1 & 0 & 0\end{array}$ & 2017 \\
\hline Corporate tax & 00100 & $\begin{array}{lllll}.20 .60 & 0 & 0 & 0\end{array}$ & 2038 & 0100 & 36 . 24. .08. & 2041 \\
\hline \multirow[t]{3}{*}{ Vat } & 01000 & $\begin{array}{lllll}.35 & .29 & 0 & 0 & .29\end{array}$ & 2031 & 0100 & 13. 27.27 .33$. & 2023 \\
\hline & \multicolumn{3}{|c|}{ Markov Model 3} & \multicolumn{3}{|c|}{ Markov Model 4} \\
\hline & $Q_{n}$ & $\lim _{n \rightarrow \infty} \hat{Q}_{n+1}=\hat{Q}$ & $S Y$ & $Q_{n}$ & $\lim _{n \rightarrow \infty} \hat{Q}_{n+1}=\hat{Q}$ & SY \\
\hline Income tax & $\begin{array}{lll}0 & 1 & 0\end{array}$ & $\begin{array}{lll}. & .38 & .43\end{array}$ & 2039 & 10 & $0,27 \quad 0,73$ & 2036 \\
\hline Corporate tax & $\begin{array}{lll}0 & 1 & 0\end{array}$ & $\begin{array}{lll}.40 & .60 & 0\end{array}$ & 2037 & 10 & $0,33 \quad 0,67$ & 2030 \\
\hline Vat & 100 & $\begin{array}{lll}.67 & 0 & .33\end{array}$ & 2020 & 10 & $0,60 \quad 0,40$ & 2021 \\
\hline
\end{tabular}

Source: Own Elaboration

Table 21: Validity of Tax Declarations

\begin{tabular}{|c|c|c|c|c|c|c|c|c|}
\hline \multirow[b]{2}{*}{ Tax Revenues } & \multicolumn{4}{|c|}{2011} & \multicolumn{4}{|c|}{2015} \\
\hline & Df & $\begin{array}{c}\qquad \mathrm{X}_{0,05}^{2} \\
\text { Critical Value }\end{array}$ & $\begin{array}{c}\mathrm{X}_{0,05}^{2} \\
\text { Test Value }\end{array}$ & $\mathrm{H}_{0}$ : Valid & $\mathrm{df}$ & $\begin{array}{c}\mathrm{X}_{0,05}^{2} \text { Critical } \\
\text { Value }\end{array}$ & $\begin{array}{c}\mathrm{X}_{0,05}^{2} \text { Test } \\
\text { Value }\end{array}$ & $\mathrm{H}_{0}$ : Valid \\
\hline Income tax & 1 & 3.841 & 1 & Accept & 2 & 5.991 & 2 & Accept \\
\hline Corporate tax & 1 & 3.841 & 2 & Accept & 1 & 3.841 & 1 & Accept \\
\hline Vat & 2 & 3.841 & 3 & Accept & 2 & 5.991 & 1 & Accept \\
\hline
\end{tabular}

Source: Own Elaboration

Table 22: Tax Declaration Predictions For 2017 According to State B of Better Models

\begin{tabular}{ccccc}
\hline Tax Declarations & Better Markov Model & Declaration Rate $\boldsymbol{r}$ (\%) & Probability (\%) & 1 - Probability (\%) \\
\hline Income tax & 1 & B or higher $61.2 \leq r$ & 37.5 & 62.5 \\
Corporate tax & 1 & B or higher $64.6 \leq r$ & 22 & 78 \\
Vat & 2 & B or higher $60.3 \leq r$ & 43 & 57 \\
\hline
\end{tabular}

Source: Own Elaboration

Table 23: Comparison of 2017 Predictions To Stationary Matrices According to Better Models

\begin{tabular}{|c|c|c|c|c|c|}
\hline Tax Revenues & Better Markov Model & 2017 Prediction & Stationary Matrix & $E\left(\hat{Q}_{17}\right)$ & SY \\
\hline Income tax & 1 & $\begin{array}{lllll}125 & .25 & .33 & .125 & .17\end{array}$ & .24 10.10 .39 .18 & 52,3 & 2038 \\
\hline Corporate tax & 1 & $\begin{array}{llll}.11 & .11 & .78 & 0\end{array}$ & $.20 .20 .60 \quad 0 \quad 0$ & 61,6 & 2038 \\
\hline Vat & 2 & $\begin{array}{llll}.14 & .29 & .27 & .30\end{array}$ & .27.33. 27. & 62,8 & 2023 \\
\hline
\end{tabular}


Original data shows that the highest base differences for income tax and VAT are 834,488,383 $€$ and 7,132,560,056 which occur at the lowest declaration rates $4.2 \%$ in 2006 and $23.7 \%$ in 2009 respectively. The highest base difference for corporate tax is $5,217,618,792$ ₹ wich occurs at the declaration rate $30.1 \%$ in 2009 . According to contingency tables 9,13 and 17 transitions of income tax, corporate tax and VAT declaration rates are declining in higher states and improving in lower states. 2017 predictions of declaration rates with respect to state B of the better models are given in Table 22.

According to model 1 of income tax declaration rates, the probabilities of five states will be stable in 2038. Income tax declaration rates more likely will be less than $61.2 \%$ in 2017 . However, in the long run income tax declaration rates would be in states $D$ or $E$ (less than 2015 realization rate) with a probability of approximately $42 \%$. A decrease of at least $19.2 \%$ which is approximately $20,267,260,000$ € from 2015 to 2038. This may cause a revenue deficiency to TRA. Probability of income tax declaration rate greater than $80.2 \%$ is declining from $12.5 \%$ in 2017 to a stable $10 \%$, that of between $61.2 \%$ and $80.1 \%$ is declining from $25 \%$ in 2017 to a stable $10 \%$ and that of $42.2 \leq r \leq 61.1$ is improving from $33 \%$ to a stable $39 \%$. Similarly, other tax revenues predictions are compared in Table 23.

A similar discussion for VAT can be given. VAT declaration rates more likely will be less than $60.3 \%$ in 2017 . However, in the long run VAT declaration rates would be in states $C$ or D (less than 2015 realization rate) with a probability of approximately $40 \%$. A decrease of at least $17.1 \%$ which is approximately $26,248,500,000$ from 2015 to 2023 . This may also cause a revenue deficiency to TRA. Therefore income tax and VAT audits should be increased by TRA. This was proposed as the only measure to be taken by TRA in "Payment Strategies in Corporate Tax: A Mathematical Analysis" study by Mavruk and Kıral (2017). However a stability or improvement is expected in corporate tax declarations from 2015 to 2038.

Income tax declaration rate was realized in state $C$ in 2015 . We predict that it improves to state $B$ in 2017 with a probability of $25 \%$ which declines to a stable $10 \%$ probability in 2038 . Corporate tax declaration rate was also realized in state $\mathrm{C}$ in 2015. It improves to state B in 2017 with a probability of $11 \%$ which improves to a stable $20 \%$ probability in 2038 . VAT declaration rate was realized in state B in 2015. It would stay in the same state in 2017 with a probability of $29 \%$ which improves to a stable 33\% probability in 2023.

The probability of income tax declaration rate greater than or equal to 0.612 would be stable at $10 \%$ by the year 2038 , the probability of corporate tax declaration rate greater than or equal to 0.646 would be stable at $20 \%$ by the year 2038 and the probability of VAT declaration rate greater than or equal to 0.603 would be stable at $27 \%$ by the year 2023 . Expected declaration rates of income tax, corporate tax and VAT in 2017 are estimated to be $52.3 \%, 61.6 \%$ and $62.8 \%$, respectively.

\section{CONCLUSION}

Tax declaration rates are predicted with respect to the results of audits provided by TRA based on 2000-2015 data. In the original data base differences has the highest values at the lowest declaration rates for two taxes. Therefore, the more tax declared by the taxpayer, the more tax revenues will be collected by the tax administration. Transition matrices show that transitions of tax declarations are declining in higher states and improving in lower states. According to prediction results all tax declaration rates more likely will be in state C or lower in 2017 according to better Markov models, and more likely will be stationary in state $C$ or lower except VAT. Income tax and VAT payoffs may substantially decrease from 2015 to 2038 and 2023 respectively. This may also cause a revenue deficiency to TRA. Therefore income tax and VAT audits should be increased by TRA. Even though tax revenues increase over time, the declaration rates show a decreasing to stationary or increasing to stationary behavior. Observed and expected declaration rates were not significantly different from each other according to Markov model 1 of income and corporate tax and Markov model 2 of VAT. Validity of the models were checked for the years 2011 and 2015 and models are found to be valid. Declaration rate predictions can be used by the TRA to take some measures against tax evasion and for tax policy revision. Central government can take the advantages of this study in the planning and improvement of tax collection process. For future studies tax payoff rates can be analyzed and predicted. This study can also be used to predict tax declaration rates of other tax revenues. 


\section{REFERENCES}

Allingham, M.G. \& Sandmo, A. 1972, “Income Tax Evasion: A Theoretical Analysis”, Journal of Public Economics, vol.1, pp. 323-338.

Usher, M.B. 1979,"Markovian Approaches to Ecological Succession”, Journal of Animal Ecology, vol.48, no.2, pp. 413-426

Serfozo, R. 2009, “Basics of Applied Stochastic Processes, Probability and its Applications”, Springer-Verlag, Berlin Heidelberg, 2

Yeh, H.W., Chan, W., Symanski, E. \& Davis, B.R. 2010, “Estimating Transition Probabilities for Ignorable Intermittent Missing Data in a Discrete-Time Markov Chain", Communications in Statistics-Simulation and Computation, vol.39, no.2, pp. 433-448.

Baasch, A., Tischew, S. \& Bruelheide, H. 2010, "Twelve years of succession on sandy substrates in a post-mining landscape: A Markov chain analysis", Ecological Applications, vol. 20, no. 4, pp. 1136-1147.

Grimshaw, S.D. \& Alexander, W.P. 2011, "Markov Chain Models for Deliquency: Transition Matrix Estimation and Forecasting", Applied Stochastic Models in Business and Industry, vol. 27, pp. 267-279.

Lipták, K. 2011, "The Application Of Markov Chain Model To The Description Of Hungarian Labor Market Processes", Zarządzanie Publiczne, vol. 4, no. 16, pp. 133-149.

Büyüktatlı, F., İşbilir, S. \& Çetin, E.í. 2013, “Markov Analizi ile Yıllık Ödeneklere Bağlı Bir Tahmin Uygulaması”, Uluslararası Alanya İşletme Fakültesi Dergisi, vol. 5, pp. 1-8

Lukić, P.,Gocić, M. \& Trajković, S. 2013, “Prediction of Annual Precipitation on the Territory Of South Serbia Using Markov Chains”, Bulletin of the Faculty of Forestry, vol.108, pp. 81-92.

Bluman, A.G. 2014, "Elemantary Statistics", McGraw Hill Education, New York.

Cavers, M.S. \& Vasudevan, K. 2015, "Brief Communication: Earthquake Sequencing: Analysis of Time Series Constructed from the Markov Chain Model", Nonlinear Process Geophysics, vol. 22, pp. 589-599

Lazri, M., Ameur, S., Brucker, J.M., Lahdir, M. \& Sehad, M. 2015, "Analysis of Drought Areas in Northern Algeria Using Markov Chains”, J. Earth Syst. Sci., vol. 124, no. 1, pp. 61-70.

Kıral, E. \& Mavruk, C. 2016, "Prediction of Central Government Budget Revenues Using Markov Model”, Journal of Cukurova University Social Sci. Inst., vol. 25, no. 2, pp. 41-56

Mavruk, C. \& Kıral, E. 2017, "Payment Strategies in Corporate Tax: A Mathematical Analysis", Manuscript to be submitted for publication.

TRA Activity Reports. 2000-2015, http://www.gib.gov.tr/kurumsal/stratejik-yonetim/faaliyet-raporlari, 5.1.2016 